\title{
School Outcomes of Children Raised by Same-Sex Parents: Evidence from Administrative Panel Data
}

American Sociological Review 2020, Vol. 85(5) 830-856

\section{(c) (i) ()}

(c) American Sociological Association 2020

DOI: $10.1177 / 0003122420957249$ journals.sagepub.com/home/asr

(3)AGE

\author{
Deni Mazrekaj, ${ }^{\text {a,b }}$ (i) Kristof De Witte, ${ }^{\text {b,c }}$ \\ and Sofie Cabus ${ }^{\mathrm{b}, \mathrm{c}}$ (iD)
}

\begin{abstract}
Although widely used in policy debates, the literature on children's outcomes when raised by same-sex parents mostly relies on small selective samples or samples based on cross-sectional survey data. This has led to a lack of statistical power and the inability to distinguish children born to same-sex parents from children of separated parents. We address these issues by using unique administrative longitudinal data from the Netherlands, which was the first country to legalize same-sex marriage. These data include 2,971 children with same-sex parents $(2,786$ lesbian couples and 185 gay male couples) and over a million children with different-sex parents followed from birth. The results indicate that children raised by same-sex parents from birth perform better than children raised by different-sex parents in both primary and secondary education. Our findings are robust to use of cousin fixed effects and coarsened exact matching to improve covariate balance and to reduce model dependence. Further analyses using a novel bounding estimator suggest the selection on unobserved characteristics would have to be more than three times higher than the selection on observed characteristics to reduce the positive estimates to zero.
\end{abstract}

\section{Keywords}

same-sex parents, administrative longitudinal data, school outcomes, coarsened exact matching, treatment effect bounds

Marriage equality is a recent victory for proponents of LGBTQ rights in the United States. On June 26, 2015, the U.S. Supreme Court legalized same-sex marriage in all 50 states, ending more than a decade of legal battles (Obergefell v. Hodges 2015). In contesting this issue, opponents of same-sex marriage made consequentialist arguments, claiming that same-sex marriage would be harmful to children and would undermine the strength of the family as an institution (McVeigh and Diaz 2009). For instance, collecting campaign advertisements from 1977 to 2013, Stone (2019) found that "children do better with a mother and a father" was central to opponents' framing from 2000 onward. Although attitudes about gay rights have become increasingly liberal, many people in the United States are still uncertain about the

aUniversity of Oxford

${ }^{\mathrm{b}} \mathrm{KU}$ Leuven

${ }^{\mathrm{c} M a a s t r i c h t ~ U n i v e r s i t y ~}$

Corresponding Author:

Deni Mazrekaj, University of Oxford, Department of Sociology, 42-43 Park End Street, OX1 1JD,

United Kingdom

Email: deni.mazrekaj@sociology.ox.ac.uk 
consequences of marriage equality for children raised by same-sex parents. In a 2019 poll in the United States, 31 percent of the adult population opposed same-sex marriage (Pew Research Center 2019).

In this article, we shed light on the consequences of being raised by same-sex parents by leveraging unique administrative longitudinal data from the Netherlands, the first country to legalize same-sex marriage. The Netherlands is particularly suitable to empirically assess outcomes of children raised by same-sex parents, as we can examine how things have played out in a nation where same-sex marriage has been in place for nearly two decades. Specifically, same-sex couples have been able to formalize their relationships through marriage since 2001, and through a registered partnership since 1998 . We can thus compare school outcomes of children raised by same-sex versus different-sex parents.

The literature on outcomes for children raised by same-sex parents mostly relies on small convenience samples or samples based on cross-sectional data (Allen 2015; Manning, Fettro, and Lamidi 2014; Stacey and Biblarz 2001). Whereas small convenience samples lack statistical power and are likely to produce biased findings, cross-sectional studies lack the ability to determine whether children actually grew up with same-sex parents or whether they lived with a same-sex couple after a parent's previous different-sex relationship. Our longitudinal data include the entire population of children born between 1998 and 2007, and their educational performance can be tracked until 2019. This enables us to study the academic achievement of 2,971 children raised by same-sex parents $(2,786$ lesbian couples and 185 gay male couples) and more than a million children raised by different-sex parents, followed from birth until the end of primary education. We follow about one third of the children until the end of secondary education (the other children were too young to have graduated from high school), enabling us to study diploma attainment. The key contribution of our analysis is that we can distinguish children who were raised by same-sex parents from birth from children of previous different-sex relationships who lived with a same-sex couple at a later date. To the best of our knowledge, this is the first study to address how children who were actually raised by same-sex parents from birth (instead of happening to live with a same-sex couple at some point in time) perform in school while retaining a large representative sample. Note, however, that these administrative data do not include a direct measure of sexual orientation. We define same-sex parents based on detailed household information from the Dutch population registers. As a result, we solely study couples, because we cannot determine whether a single-parent identifies as gay.

Our results indicate that children raised by same-sex parents from birth outperform children raised by different-sex parents on standardized test scores at the end of primary education by about .14 standard deviations. By contrast, children who live with same-sex parents at a later date perform worse (albeit not significantly) on the test than children with different-sex parents, likely due to the negative influence of parental separation (see review in McLanahan, Tach, and Schneider 2013). ${ }^{1}$ We also find that children raised by same-sex parents from birth continue to outperform children raised by different-sex parents in secondary education. In particular, the results suggest children raised by same-sex parents from birth are 4.8 percentage points more likely to graduate from high school than are children raised by different-sex parents. We do not find any heterogeneity by child's sex, ethnicity, or parental marital status. Similarly, we find little heterogeneity by parents' sex, although our sample of gay male parents is too small to draw any strong conclusions.

Our results mostly support the hypothesis that, given the time-consuming and costly procedures for same-sex couples to obtain children, same-sex parents typically have higher socioeconomic status resulting in better school outcomes. Nonetheless, when we control for a range of socioeconomic factors, the significantly positive association does not entirely disappear. We use a novel bounding 
estimator developed by Oster (2019) to bound the causal effect of being born and raised by same-sex parents. Treatment effect bounds indicate that the selection on unobserved characteristics, such as parental motivation and family planning before having children, would have to be more than three times higher than the selection on observed characteristics, such as parental education and income, to reduce the positive association to zero. Overall, we conclude that children raised by same-sex parents are likely to perform at least as well as (if not better than) children raised by differentsex parents in school.

\section{BACKGROUND}

\section{Outcomes of Children Raised by Same-Sex Parents: Previous Empirical Evidence}

A sizeable interdisciplinary literature has studied the association between same-sex parents and children's well-being (for recent overviews, see Allen 2015; Manning et al. 2014). Findings from this research were crucial in the U.S. Supreme Court decision to legalize same-sex marriage in 2015. The empirical literature suggests children raised by same-sex parents perform just as well as children raised by different-sex parents on a range of outcomes, including health (Cenegy, Denney, and Kimbro 2018; Reczek et al. 2016), social skills (Fedewa and Clark 2009; Gartrell and Bos 2010), behavior problems (Reczek et al. 2017), psychological wellbeing (Wainright, Russell, and Patterson 2004), and education (Boertien and Bernardi 2019; Rosenfeld 2010; Watkins 2018) (for contrary findings, see Allen 2013; Regnerus 2012; Sarantakos 1996; Sullins 2015a).

Although the consensus in the social science literature appears to be that children of samesex parents perform at least as well as children of different-sex parents, previous research has a key shortcoming due to data unavailability. Namely, studies have either used small convenience samples to track children's family structure from birth, or large representative datasets that are cross-sectional and therefore only able to identify children who happened to live with same-sex parents at one point in time. Most studies that track children from birth use convenience samples (Gartrell and Bos 2010; Golombok, Tasker, and Murray 1997; MacCallum and Golombok 2004; Sarantakos 1996) or very small representative samples (Cheng and Powell 2015; Fedewa and Clark 2009; Potter 2012; Regnerus 2012; Sullins 2015b; Wainright et al. 2004). Such samples have low validity and statistical power, making inferences from them questionable.

Recent studies have addressed the issues of selective and small samples by using census data. Specifically, Rosenfeld (2010) used 2000 U.S. census data and found that children with same-sex parents were equally likely to progress normally through school as were children with different-sex parents. Allen, Pakaluk, and Price (2013, 2014), however, estimated a negative association between same-sex parents and progress through school using the same data as Rosenfeld (2010), but they used a different way of accounting for socioeconomic status. Similarly, using 2006 Canadian census data, Allen (2013) estimated that children with same-sex parents were less likely to graduate from high school than children with different-sex parents. More recently, using the 2012, 2013, and 2014 waves of the American Community Survey (ACS), Watkins (2018) reanalyzed progress through school as an outcome and found no significant differences between children with samesex versus different-sex parents. Extending the analyses to 2008 to 2015 ACS waves, Boertien and Bernardi (2019) confirmed these findings and found no differences between children with same-sex versus different-sex parents regardless of how socioeconomic status is accounted for. Their study also showed that children with same-sex parents used to be more likely to be behind in school in areas with unfavorable legal environments and attitudes toward same-sex couples, but this association has disappeared over time.

Although these studies use large representative samples, census data provide only a 
cross-sectional snapshot of family structure. As a result, these studies do not analyze school performance of children who were raised by same-sex parents from birth, but rather the school performance of children who lived with same-sex parents at any point in time. This is an important limitation because many children live with a same-sex couple after a parent's separation from a different-sex partner, and therefore they were not raised from birth by same-sex parents (Biblarz and Stacey 2010; Stacey and Biblarz 2001). Moreover, parental separation may exert an independent negative effect on school outcomes (McLanahan et al. 2013). Consequently, studies based on these data may mistakenly attribute a negative coefficient to living with same-sex parents, as associations may be biased downward.

Another limitation of census data is misclassification of same-sex parents due to misreporting. This is a common issue when studying a small population, but it is especially prevalent when studying same-sex couples, given that many U.S. censuses were compiled when same-sex marriage was unlawful. The U.S. Census Bureau estimated that about one-half of respondents reporting as same-sex married couples in the 2010 ACS were actually different-sex married couples who misreported on the sex question (Kreider and Lofquist 2015). As a result, the U.S. Census Bureau retracted its 2010 estimate of the number of same-sex couples in the United States (O'Connell and Feliz 2011). Given that this type of measurement error is not classical, it is unclear in which direction the endogenous coefficients are biased. Finally, in the absence of a measure of student achievement such as standardized test scores, studies that use U.S. census or ACS data are limited to a crude measure of progress through primary school calculated using current age and highest grade completed. ${ }^{2}$

In terms of prior work, Aldén, Björklund, and Hammarstedt's (2017) paper comes closest to our study. Similar to our design, they used administrative population data to compare health outcomes of about 750 children with lesbian parents to the health outcomes of children with different-sex parents in Sweden. They followed these children until age 10 and found a positive association between living with lesbian parents and having favorable health outcomes. They also showed that lesbian couples in Sweden tend to be more educated than different-sex couples, and children with lesbian parents particularly benefit from their mothers' higher socioeconomic status in terms of health. In additional analyses, they estimated a positive association between living with lesbian parents and children's mathematics and language test scores. However, due to data unavailability, the authors could analyze school outcomes for only 56 children with lesbian parents.

\section{Theoretical Perspectives}

Several theoretical perspectives from the fields of sociology, biology, psychology, and economics suggest that children raised by samesex parents are likely to perform worse in school. First, the specialization theory suggests children may need a parent of each sex because parents differ in their parenting styles, and mothers and fathers teach different skills (Allen 2013). Second, the kin selection theory suggests that due to evolution, and because parents incur economic, physical, and mental costs in raising children, they display discriminative parenting and invest most in biological children (Hamilton 1964). Given that at least one same-sex parent in a couple is not the child's biological parent, ${ }^{3}$ kin selection theory predicts that total parental investment will be lower for same-sex parents than for differentsex parents. Finally, the discrimination theory suggests same-sex parents may face increased stressors due to their sexual orientation (Stacey and Biblarz 2001), such as persistent stigma from society and negative feedback from family and friends who question the authenticity of their roles as parents. For instance, DiazSerrano and Meix-Llop (2016) found that schools were more hesitant to interact with same-sex parents than with different-sex parents. In turn, children of same-sex parents may be affected 
by the discrimination their parents face (Bos et al. 2004; McLanahan et al. 2013) and perform worse in school as a result. Children of same-sex parents can also directly experience discrimination by being bullied about their parents' sexual orientation (Perrin et al. 2019), leading to lower school performance (Robinson and Espelage 2011).

These theoretical perspectives suggest negative outcomes for children raised by same-sex parents, but they do not consider the selection of same-sex couples into childrearing. Same-sex couples may have children through a previous different-sex relationship, through adoption, or through fertility treatments. ${ }^{4}$ As previously mentioned, parental separation may exert an independent negative effect on school outcomes (McLanahan et al. 2013), leading to a negative selection effect. By contrast, adoption and fertility treatments are likely to result in a positive socioeconomic selection effect, as these procedures are cumbersome and expensive. In the Netherlands, for instance, same-sex couples have been able to adopt Dutch children (often from foster care) since the legalization of same-sex marriage in 2001, and foreign-born children since 2009 . The costs for adoption typically range between 15,000 and 40,000 euros, and the costs for artificial insemination are about 1,500 euros per treatment, with a success rate of about 15 percent. ${ }^{5}$ The costs are similar or even higher in other countries, such as the United States, where adoption costs range from 15,000 to 40,000 USD and one cycle of IVF may cost up to 13,000 USD (Bell 2019).

Given the time-consuming and costly procedures to have children, the literature has often found that same-sex parents have higher socioeconomic status (e.g., higher levels of income and education) than do different-sex parents (Aldén et al. 2017; Boertien and Bernardi 2019; Watkins 2018). Moreover, samesex couples may be highly motivated to become parents and may therefore take additional steps, such as considerable family planning. In other words, high costs of childrearing may discourage less committed same-sex couples from having children. Similarly, a higher proportion of different-sex couples' family formation may involve unintended pregnancies. The child development literature shows that beneficial socioeconomic characteristics and parental motivation play a pivotal role in children's outcomes (Cunha and Heckman 2007; Cunha, Heckman, and Schennach 2010; Heckman 2006). Thus, we hypothesize that once we consider same-sex parents who raised children from birth, potentially higher socioeconomic status and parental motivation are likely to neutralize the negative predictions of the specialization and kin selection theories in terms of parental skills and investment. Therefore, we speculate that children raised by same-sex parents will perform at least as well in school as children raised by different-sex parents. By contrast, we hypothesize that, due to parental separation, children who were born into different-sex relationships but later live with same-sex parents will perform worse in school than children raised by different-sex parents.

A further reason to expect parental investment to be high among children raised by same-sex parents is that most same-sex couples that self-select into childbearing are lesbian couples, as the barriers for lesbian couples to have children are typically lower than for gay couples (Kolk and Andersson 2020). For instance, in the administrative data in Sweden (Aldén et al. 2017), 95 percent of children living with same-sex parents were raised by lesbian mothers (equal share as in our data). Similarly, in the American Community Survey, 70 percent of children with same-sex parents had lesbian parents (Boertien and Bernardi 2019). Given that many countries, including the Netherlands, allow for known donors (e.g., relatives or friends) when considering artificial insemination, lesbian parents are likely to choose donors with favorable characteristics, such as ability. Moreover, lesbian couples conceiving via donor insemination also go through a selection process to determine which of the two mothers will carry the child. These genetic traits are likely to positively influence children's outcomes (Herd et al. 2019). 
The literature also suggests that children with lesbian parents are likely to receive a "double dose of motherhood" (Biblarz and Stacey 2010). In a review of the previous literature, most of which used very small samples, Biblarz and Stacey (2010) found that mothers spend more time with their children, and their parenting style tends to be especially beneficial for child development. As a result, families consisting of two mothers may exhibit an increased effort in caretaking, communication, and intimacy with their children. This is supported by findings from the American Time Survey (Prickett, MartinStorey, and Crosnoe 2015). Specifically, the authors found that lesbian parents were significantly more likely to spend time with their children than were both gay male parents and different-sex parents.

Just as the negative effects predicted by the specialization and kin selection theories can plausibly be neutralized or reversed because of the selection of same-sex couples into childrearing, compensation theory predicts that the negative effects of discrimination toward same-sex parents can be reversed (Hamilton, Cheng, and Powell 2007). This theory posits that even if same-sex parents face substantive barriers to parenthood, they channel these stressors as motivation to prove themselves as good parents. As noted earlier, Prickett and colleagues (2015) found that same-sex parents spend more time with their children than do different-sex parents. Thus, compensation theory predicts that children raised by same-sex parents are likely to perform just as well as, if not better than, children raised by different-sex parents, even in the presence of discrimination toward samesex couples. A testable implication of both the discrimination and the compensation theory is that the introduction of same-sex marriage in 2001 may have changed the association between living with same-sex parents and children's outcomes. If the discrimination theory holds, we would expect a more positive association after the introduction of same-sex marriage, given that attitudes toward same-sex couples have improved. By contrast, if the compensation theory drives parental behavior, the association should have remained unchanged or reduced after the introduction of same-sex marriage, as samesex parents should have less incentive to increase their parental effort in response to societal barriers.

In summary, we hypothesize that selection effects arising from increased parental investment are the primary driver of the association between living with same-sex parents and children's outcomes. Children with same-sex parents are more likely to have high socioeconomic status and receive substantial parental investment from highly committed parents. Therefore, we predict that children with same-sex parents are likely to perform at least as well as (if not better than) children with different-sex parents.

\section{DATA}

\section{Sample Construction}

We use unique administrative records collected by Statistics Netherlands that cover the entire Dutch population annually from 1995 to 2019. These administrative records are based on automated municipal population registers (Steenhof and Harmsen 2003). Every municipality in the Netherlands has its own population register containing information on all inhabitants of that municipality. Each Dutch inhabitant is given a unique personal identification number, allowing us to link their data to those of their children, parents, and partners. We can identify people as parents because they must register their children at the municipality within three days after a child is born. In case of adoption, the municipality receives the information on the child-parent relationship from the court that granted the adoption. Thus, for each child identifier, the municipal registers we use also include a father identifier (can be male or female) and a mother identifier (can also be male or female) as well as information on whether the child was adopted and the year of adoption. The municipal registers also include 
the address of residence annually for each person in the Netherlands, so we can identify a household as individuals living at the same address. We also have identifiers for each partner of an individual, as well as marital status, enabling us to identify stepparents. Individuals are considered married based on a marriage certificate, in a registered partnership based on a registered partnership certificate, or as cohabiting. The latter is determined based on either a cohabitation agreement or by being registered as a fiscal partner in the Dutch tax administration while living at the same address and not being married or in a registered partnership. Finally, the municipal registers include demographic characteristics (i.e., date of birth, sex, ethnicity, birth country), and income information from the tax authorities. We obtained education data from the education registers. For each child, we have information on student achievement in primary education between school years 2008-2009 and 2018-2019. For about one third of these children, we also have information on diploma attainment in secondary education. The education registers also include information on whether a child's parents obtained a high school diploma.

In summary, using child, parent, and partner identifiers, we can link all children to their parents and their parents' partners. Moreover, we can identify with whom children reside based on each individual's address. ${ }^{6} \mathrm{We}$ can also observe family structure-married, registered partnership, cohabiting, or adopted - as well as demographic information and income of parents and stepparents. Finally, we can discern whether parents obtained a high school diploma, and we can study academic achievement in primary education and diploma attainment in secondary education as outcomes.

Our administrative and longitudinal data offer four advantages over the cross-sectional census data used in previous studies. The first two advantages pertain to identification of same-sex parents. First, for each year, we can determine whether children actually lived with their parents in the same household.
Unlike the census data, the municipal registers enable us to go beyond a cross-sectional snapshot of family structure and analyze school outcomes of children who were actually raised by same-sex parents from birth while retaining a large representative sample. Similarly, we can determine whether and when children lived with a same-sex couple. This is an important advantage over studies based on census data, as we can determine whether children were born to same-sex parents or if they lived with a same-sex couple after parental separation. Moreover, we know whether and when a child was adopted. Second, unlike studies using census data, we cannot mistake relatives (e.g., grandparents, aunts, uncles) who live in the same household as the child's parents, because these relatives also have unique identifiers that differ from parental identifiers. In census data, all relationships within a household are observed in relation to the head of the household. For instance, if children live with their parents and their grandparents in their grandparents' home, the head of the household would be the grandfather. If the grandparents are heterosexual, census data would show the child as living with a different-sex couple, regardless of whether the actual parents are a same-sex couple. Our sample includes an identifier and the sex of both the parents and the grandparents, so we can determine whether a child's parents are a same-sex couple, even if the grandparents are a different-sex couple.

The next two advantages pertain to the outcome and the control variables. Most of our data are annual over a more than 20-year period, so we can construct characteristics (e.g., household income) before children began living with a same-sex couple. Because we measure characteristics at birth, we can limit endogeneity issues arising from control variables measured at the time or even after treatment, as occurs in studies using census data (Elwert and Winship 2014). The last advantage of our data is that we study student achievement in primary education based on standardized high-stakes test scores-for earlier cohorts, we can also include diploma 
attainment - instead of a crude measure of progress through school or test scores evaluated by teachers (which are likely subjective measures) as used in most studies.

To study school outcomes of children raised by same-sex parents, we restrict the sample in five ways. First, as a measure of student achievement, our data include scores from standardized tests conducted in the final year of primary education (see the Educational Outcomes section), when students are typically 12 years old. We remove children who had not reached the last grade of primary education by 2018-2019 (last school year in the data), as these children are not yet old enough to take the test. Second, our data do not include a direct measure of sexual orientation, so we restrict the sample to couples. We do not include children in single-parent families, because we cannot determine a single-parent's sexual orientation from our data. Following Watkins (2018) and Boertien and Bernardi (2019), who used the American Community Survey, we removed these children from the analysis (14.23 percent of the sample). We also tried an alternative approach in which we consider single-parents to be heterosexual. These results are available in Table $\mathrm{S} 1$ in the online supplement and are very similar to the main results. Third, we do not include children who were in an institution such as an orphanage, as their caretakers do not fall within the common definitions of same-sex or different-sex parents. Fourth, we only consider children born since 1998, as this was the first year same-sex couples could formalize their relationship through a registered partnership (and later in 2001 through a marriage). Finally, we remove a small percentage (.04 percent) of children with missing control variables, none of whom were living with same-sex parents. The final sample includes 1,204,692 children born between 1998 and 2007.

\section{Children with Same-Sex Parents}

Our administrative data do not include a measure of sexual orientation, so we do not know whether parents identify as gay or straight.
We identify children living with same-sex parents through household composition based on the address of all individuals and the sex of each household member. We first identify a household as all people living at the same address. We then note the parental identifiers and the partner identifiers according to the child-parent and individual-partner relationships explained in the previous section. Given that we study couples, two possibilities can occur in our data in a given year: either the child lived with both (possibly adoptive) parents, or with a parent and a stepparent. Thus, for each year from birth until 2019, we can determine whether a child resided with parents or stepparents at the same address and the parents' sex. If a child lived with parents or stepparents who are both male or both female, we conclude that the child lived with gay or lesbian parents, respectively, that year. In the analyses, we use an indicator with a value of 1 if the child lived with same-sex parents at least one year from birth until the outcome was measured, and a value of 0 if the child lived with different-sex parents. We also estimated models with a continuous variable indicating the number of years spent with same-sex parents, as we can precisely determine when a child entered such a living arrangement. These results are presented in Table S2 in the online supplement and lead to very similar conclusions. Because some of the models cannot be estimated using a continuous variable, we opted for a dummy variable in the main analyses.

In total, we observe 1,204,692 children, of which 2,971 children (.25 percent) live with same-sex parents. Only 185 children live with gay male parents. This low number of children living with gay male parents is likely due to three reasons. First, as in most countries, little legal progress has been made facilitating the path to biological children for gay male couples in the Netherlands; the birth mother is the child's legal mother, regardless of arrangements made before the child's conception. The situation becomes even more complicated if the birth mother is in a married relationship with another partner. For a gay male couple to 
become legal parents of the child, the legal mother would first have to be divested of her parental responsibility through a complicated legal procedure. Afterward, the gay male couple would have to file for joint adoption through another cumbersome legal procedure. This process does not apply to lesbian couples, as one of the lesbian parents is usually also the birth mother. Second, it was only in 2019 that two clinics started performing surrogacy procedures for gay male couples. Finally, in the Netherlands, children typically live with their mother after parental separation. Thus, in our dataset, children who live with a same-sex couple after separation of their different-sex parents are likely to live with a lesbian couple. If the mother were gay, the child would reside with the mother and her new gay partner. If the father were gay, the child would almost certainly reside with the heterosexual mother and her new partner. Note, however, that our data do not include post-separation arrangements between parents. Thus, a child might live half the time with the heterosexual mother and half the time with the gay father. In our data, this arrangement would appear as living solely with the mother, and we would count this child as living with different-sex parents. In summary, given the low sample size of children living with gay male parents, we mostly refrain from making statements about the potential heterogeneity in findings by sex of the parents. Nonetheless, we show the main results for lesbian and gay male parents separately in Table S3 in the online supplement. The results for gay male parents support the main conclusion, but they are not significant, likely due to low statistical power. Thus, although our results are primarily driven by lesbian parents, we obtain a similar conclusion for gay male parents.

As mentioned earlier, we use the group of children who lived with same-sex parents for at least one year as the treatment group of interest in the main analyses. However, this group is heterogeneous: it includes children who were born to same-sex parents, children from a parent's previous different-sex relationship, and adopted children (often from foster care). Although our data do not include information on how same-sex couples obtained children (e.g., we do not know whether a couple used donor insemination), we do know when a child started living with a same-sex couple and whether the child was adopted or was previously in foster care. We also know whether and when parents separated, so we can divide children living with same-sex parents into three groups: birth children, adopted children, and children from a previous different-sex relationship. Birth children (1) have lived with same-sex parents from birth and (2) were neither adopted nor in foster care. These children have spent their entire childhood, until the outcome was measured, living with same-sex parents. Adopted children could also have been raised by samesex parents from birth, but they may have very different characteristics than other birth children. Therefore, we treat adopted children as a separate category and do not consider them as birth children. We identify 1,390 birth children in our sample. Note that it is still possible that birth children experienced parental separation: a child could have been born into a same-sex family, the parents later separated, and the child's parent then partnered with another same-sex partner. Indeed, our data show that 6.69 percent of birth children experienced parental separation. Thus, children born to same-sex parents but who experience parental separation at a later age are still counted as birth children.

Next, we identify 50 children living with same-sex parents who were adopted or who lived with foster parents. ${ }^{7}$ As expected due to the cumbersome and costly adoption procedures, adoption is not common among samesex couples in the Netherlands. Because this group of children is very small, we make no further distinction between adopted children and children living with foster parents. Moreover, we do not distinguish between children who were adopted at birth versus at a later age. ${ }^{8}$

Finally, we identify 1,531 children living with same-sex parents who previously lived with different-sex parents. These children are neither birth children nor adopted children; 


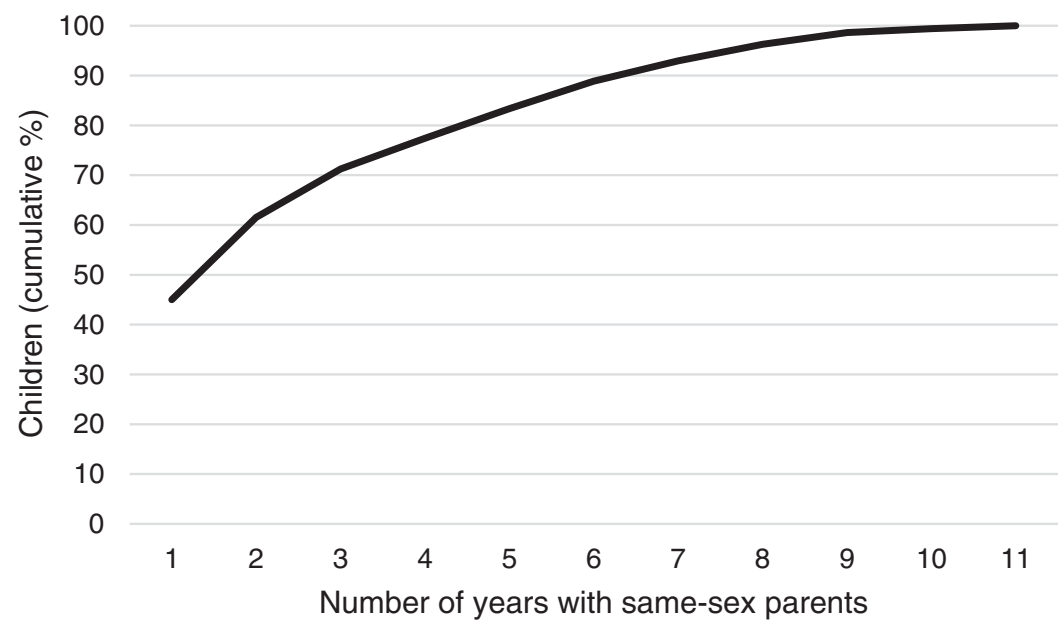

Figure 1. Cumulative Number of Years Children from Previous Different-Sex Relationships Spent Living with Same-Sex Parents $(N=1,531)$

they began living with same-sex parents after birth. Figure 1 presents the cumulative number of years spent with same-sex parents for these children. Only about 17 percent of children from a previous different-sex relationship spent more than five years living with same-sex parents (median $=2, \mathrm{SD}=2.42$ ). The relative stability of same-sex and differentsex partnerships is an important issue in the literature. For instance, whereas Kalmijn, Loeve, and Manting (2007) found that samesex couples were more likely than differentsex couples to separate in the Netherlands, Rosenfeld (2014) found no difference in the United States. Our data confirm Kalmijn and colleagues' (2007) findings. We have already mentioned that 6.69 percent of all birth children experienced parental separation. However, for all children living with same-sex parents, the percentage of children who experienced parental separation rises to 54.86 percent. By contrast, 19.44 percent of children with different-sex parents experienced parental separation.

In summary, the group of 2,971 children with same-sex parents can be divided into 1,390 birth children (46.79 percent), 50 adopted children (1.68 percent), and 1,531 children from a previous different-sex relationship (51.53 percent).

\section{Educational Outcomes}

Our outcome variables closely follow the main transition points in the Dutch education system, which provides compulsory education beginning at age 5 and continuing until age 18 (or younger if a student obtains a high school diploma earlier). Primary education lasts seven years, until age 12 . In secondary education, students enter a system with three main tracks: pre-vocational (VMBO), general (HAVO), and pre-university (VWO). The pre-university track is considered the most prestigious. Students decide on a secondary-education track based on a standardized test in the final year of primary education (age 12) and their teacher's recommendation. ${ }^{9}$ We use the score on this standardized test as our primary outcome of interest, as it is an objective measure of student achievement. In additional analyses, we also used teacher's recommendation at the end of primary education as an outcome (see Table S5 in the online supplement). We code this variable as an indicator with a value of 1 if the teacher advised the pre-university track, and 0 otherwise. We do not present these results as part of the main analyses because teacher's recommendation is by definition a subjective opinion. Nonetheless, this outcome yields analogous conclusions as the standardized test. 
Schools may choose from several standardized tests. Although the tests may differ by school, all students within a school complete the same standardized test. In practice, these tests are very comparable. Nonetheless, most schools use the Central Institute of Test Development test (CITO-test), which includes multiple choice questions testing students' Dutch and comprehension skills, mathematics, world orientation (involving geography, biology, and history), and study skills. It is considered a high-stakes test by students and parents and is also used for school evaluation (Scheerens et al. 2012). Of the children in our sample, 78.39 percent took the CITO-test. To maximize sample size, we use other tests as well, but if we solely consider the CITO-test, our results remain very similar (see Table S6 in the online supplement). To make test scores comparable across different tests and years, we standardize scores by the test and year to have a mean zero and unit variance.

For about one third of the population, we also have diploma attainment in secondary education. Other children were too young to have graduated from high school. This variable is measured as an indicator with a value of 1 if the student obtained an upper-secondary diploma by 2019 according to the International Standard Classification of Education framework (i.e., qualification at ISCED 2011 level 3), and 0 if the student was a high school dropout.

\section{Control Variables}

At the individual level, we control for a child's sex (1 is boy, 0 is girl) and year of birth. As a measure of socioeconomic background, we include six variables. First, we construct a variable for a child's ethnicity based on parental birth country, which includes four categories: (1) both parents were born in the Netherlands; (2) one parent was born in the Netherlands, the other parent was born in a Western country, such as a European Union country or the United States; (3) one parent was born in the Netherlands, the other parent was born in a non-Western country; and (4) both parents were born outside the Netherlands. Similar to Watkins (2018), who found that children with samesex parents are more likely to be white, we control for children of same-sex parents likely having parents born in the Netherlands rather than parents who emigrated from more conservative countries such as Turkey or Morocco. Second, we include an indicator for parental education with a value of 1 if at least one parent did not complete upper-secondary education and 0 otherwise. ${ }^{10}$ We also include a continuous measure for household net income in euros. Calculation of this variable takes three steps. First, we calculate total net income per year as the sum of gross income within a year minus the amount of taxes paid. We perform this calculation for each of the child's parents or stepparents. Then, we obtain the net household income per year as the sum of either the parents' or stepparents' annual net incomes, depending on with whom the child resides in a given year. Finally, we take the logarithm of household income to smoothen the income distribution and to interpret the coefficients in percentages. Rosenfeld (2010) found that measures of parental education and income account for most of the differences between children with same-sex versus different-sex parents. We also include indicators for neighborhood of residence (a more detailed level than municipality) to account for children of same-sex parents potentially being located in wealthier neighborhoods (Aldén et al. 2017; Black et al. 2002). Finally, we include a continuous variable for parents' average age and for family size (number of children in the household), given that same-sex couples are typically older and have fewer children than differentsex couples (Aldén et al. 2017; Black, Sanders, and Taylor 2007).

As a last control variable, we include a trichotomous indicator for family structure: married parents, cohabiting parents, and other. The category other includes children with a parent and a stepparent as well as adopted children and foster children. ${ }^{11}$ The distinction between married and cohabiting parents is used in most studies of same-sex 
parenting (Allen 2013; Rosenfeld 2010; Watkins 2018). Although both marriage and registered partnership are found in the municipal registers, we do not distinguish between the two because, in practice, a registered partnership is an almost perfect substitute for marriage in the Netherlands (Trandafir 2014). Nonetheless, the results presented in Table S7 in the online supplement indicate that our conclusions are robust to treating marriage and registered partnership as separate categories.

Unlike previous cross-sectional studies that used census data, we chose to primarily measure neighborhood, household income, average age of parents, family size, and family structure at child's birth, rather than time of the test. This is because many children first live with same-sex parents later in their lives after a gay parent comes out. Thus, these variables are likely to be influenced by a parent's coming out and are therefore endogenous to a child living with same-sex parents. This leads to post-treatment bias (Rosenbaum 1984), also known as "collider bias" (Elwert and Winship 2014) or "bad control bias" (Angrist and Pischke 2009). For instance, neighborhood of residence at the time of the test may be endogenous to residing with same-sex parents as, after coming out, gay parents are likely to live in wealthier neighborhoods (Black et al. 2002), and wealthier neighborhoods may positively influence school outcomes (Wodtke, Elwert, and Harding 2016; Wodtke, Harding, and Elwert 2011). On the other hand, measuring control variables at birth may hide changes in these variables over time. For instance, household income at birth may underestimate true household income, as many mothers did not work during pregnancy or were on reduced pay. Therefore, we perform additional analyses in which we also include control variables at the time of the test, their squared terms and two-way interactions, and the number of residential changes (number of times a child changed address) (see Table S8 in the online supplement). In an additional model, we also control for the school a child went to at the time of the test. The results remain robust to these additional specifications.

\section{METHODS}

\section{Linear Regression Analysis}

We estimate school outcomes among children living with same-sex parents by an ordinary least squares $(\mathrm{OLS})^{12}$ model that is formulated as follows:

$$
y_{i}=\alpha_{0}+\beta_{1} H_{i}+\boldsymbol{\theta} \boldsymbol{X}_{\boldsymbol{i}}+\varepsilon_{i}
$$

where $y_{i}$ is the outcome variable of child $i$ (i.e., the standardized test score at the end of primary education and diploma attainment in secondary education). The variable of interest is $H_{i}$, with value 1 if the child lived with same-sex parents at least one year and 0 if the child lived with different-sex parents. The parameter of interest is $\beta_{1}$, representing the influence of residing with same-sex parents on school outcomes. Depending on the specification, Equation 1 also includes control variables defined above as part of $\boldsymbol{X}_{\boldsymbol{i}}{ }^{13}$ Each specification is estimated using clustered standard errors at the neighborhood level to account for dependence of observations within neighborhoods. Nonetheless, our results are robust to clustering standard errors at the household level to account for siblings (see Table S9 in the online supplement).

Several points about Equation 1 are worth mentioning. The comparison between children living with same-sex and different-sex parents is econometrically challenging. Because children from parents' previous different-sex relationships begin living with a same-sex couple around the period of separation, the effect of living with same-sex parents is conflated with the potential independent negative effect of family instability (McLanahan et al. 2013). Moreover, as seen in Figure 1 , these children often did not live with samesex parents for a long time. Similarly, adopted children and foster children may face exceptional challenges during their lives and may be at disproportionate risk of adverse outcomes (Doyle 2007; Font et al. 2018). Consequently, we are unable to separate the effect of living with same-sex parents from the independent effects of parental separation and adoption. 
There is considerable disagreement among sociologists about how to treat children from a previous different-sex relationship and adopted children. Whereas Rosenfeld (2013) argues that these children should be dropped from the analysis, Allen and colleagues (2013) argue that they should be included. To reconcile the two approaches, we estimate a model with all children included, as well as a model without children from previous differentsex relationships and adopted children. In addition, we estimate a model with the number of family transitions and indicators for adoption and foster parents as control variables. These results yield similar conclusions as the main results (see Table S12 in the online supplement). Nonetheless, as mentioned earlier, these variables are endogenous and therefore bad controls (Angrist and Pischke 2009; Elwert and Winship 2014; Rosenbaum 1984), so we do not include them in our preferred model specification. We also present results solely for children from previous different-sex relationships and adopted children (with children raised by same-sex parents from birth excluded) in Table S12. These results are merely suggestive, as they are prone to considerable selection bias.

\section{Matching Analysis}

Despite our data including 1,390 children who were raised by same-sex parents from birth, these children represent less than 1 percent of the total sample. As a result, the treatment group of children raised by same-sex parents is much smaller (and therefore less heterogeneous) than the control group of children raised by different-sex parents. To account for this, we perform coarsened exact matching (CEM) as in Blackwell and colleagues (2009) and Iacus, King, and Porro (2012). The goal of CEM is to reduce the imbalance in covariates and reduce model dependence stemming from a disproportionately large control group. This imbalance between the treated and control groups may lead to bias in the treatment effect (Ho et al. 2007). CEM reduces this imbalance by matching each child raised by same-sex parents with a child raised by different-sex parents who has either exactly the same observed characteristics (exact matching) or very similar observed characteristics based on narrow categories (coarsened exact matching) (here, observed characteristics in $X_{i}$ in Equation 1). Iacus and colleagues (2012) found that CEM performs better than OLS and the commonly used propensity score matching (PSM) in estimating causal effects. Nonetheless, we also conduct PSM and obtain similar results (see Table S8 in the online supplement).

To perform CEM, we coarsened several continuous control variables. Household annual net income is coarsened to deciles of the income distribution, and parents' average age and family size are coarsened to categorical variables (younger than 25, 26 to 30, 31 to 35, 36 to 40, 41 to 45, older than 45; and only child, two children, three or more children, respectively). The rest of the control variables are already categorical and did not need any coarsening. Due to a large control group that includes more than a million children living with different-sex parents, we searched for an exact match on all the covariates.

\section{Bounding Analysis}

A word of caution is necessary about causal interpretation of our findings. Unlike earlier studies, our administrative longitudinal data enable us to identify children who were born to same-sex parents versus children who happen to live with same-sex parents at a certain point in time. Nonetheless, although we control for the main observable characteristics (selection on observables), we are unable to control for unobservable characteristics (selection on unobservables). As mentioned in the theoretical section (see also the Sample Characteristics section in Results), same-sex parents are likely to have higher socioeconomic status than different-sex parents due to the cumbersome and costly procedures they must go through to have children. In addition to selection on observed characteristics, children living with same-sex parents may also be 
selected on unobserved characteristics, such as ability and parental motivation. To the extent that these selection issues apply to same-sex couples, we would expect our results to represent an upper bound of the causal effect of being raised by same-sex parents.

To explore these selection effects in more depth, we perform an additional analysis using a novel bounding estimator developed by Oster (2019), which generalizes the bounding analysis first used by Altonji, Elder, and Taber (2005). By analyzing coefficient and $R^{2}$ movements before and after the inclusion of observed characteristics, we can calculate how large the effect of unobserved characteristics would have to be compared to the effect of observed characteristics to explain away the result. Specifically, the bounding analysis proceeds in three steps. We first start with estimating Equation 1 with none of the control variables included (uncontrolled regression). Then, we re-estimate Equation 1 with all the control variables included (controlled regression). This exercise is often performed to suggest that if a coefficient is stable after the inclusion of observed control variables, the omitted variable bias is likely limited. Implicitly, this approach assumes that selection on observables is informative about the selection on unobservables. Oster (2019), however, shows that coefficient movements only are not sufficient to characterize the selection on unobservables. Namely, the selection on unobservables also depends on how much of the variance in the outcome is explained by the inclusion of observed characteristics. Therefore, it is necessary to also observe $R^{2}$ changes between the uncontrolled and the controlled regression.

The key parameter of interest is the selection ratio. Intuitively, this ratio determines how large the effect of unobserved characteristics would have to be compared to the effect of observed characteristics to explain away the result. When the selection ratio is 1 , the unobservable characteristics (e.g., ability or parental motivation and family planning before having children) would have to be just as important as the observed characteristics (e.g., parental education, income, family structure) to arrive at zero association between residing with same-sex parents and educational outcomes. To calculate the selection ratio, Oster (2019) uses the following equation:

$$
\beta^{*} \approx \tilde{\beta}-\delta[\dot{\beta}-\tilde{\beta}] \frac{R_{\max }-\tilde{R}}{\tilde{R}-\dot{R}}
$$

where $\beta^{*}$ is selection-bias adjusted effect of residing with same-sex parents on school outcomes, $\widetilde{\beta}$ is the influence of residing with same-sex parents on school outcomes obtained from the controlled regression, $\dot{\beta}$ is the influence of residing with same-sex parents on school outcomes obtained from the uncontrolled regression, and $\delta$ is the selection ratio. Correspondingly, $\widetilde{R}$ is the $R^{2}$ from the controlled regression and $\dot{R}$ is the $R^{2}$ from the uncontrolled regression. Note that these are $R^{2}$ from the regressions, and not the adjusted $R^{2}$. Equation 2 also includes the parameter $R_{\max }$, that is, the maximum value of $R^{2}$ in the theoretical population that we could attain if we observed all possible explanatory variables. This parameter is unobserved and needs to be specified. At first sight, it may look as if $R_{\max }$ should be 1 . However, not all variables that explain the variation in school outcomes also bias the relationship between residing with same-sex parents and school outcomes. The bounding analysis assumes that only factors associated with both the treatment of interest (residing with same-sex parents) and the educational outcomes can potentially confound the results. Moreover, $R_{\max }$ of 1 assumes there is no measurement error in school outcomes. In her analysis, Oster (2019) found that setting $R_{\max }$ of 1 rejects all the associations, even if they represent true associations. Therefore, we follow Oster's (2019) recommendation to set $R_{\max }$ at 1.3 times $R^{2}$ from the controlled regression. ${ }^{14}$

We use Equation 1 to provide coefficient estimates when setting different values of the selection ratio $\delta$. These coefficient estimates depend on the effect of the observed characteristics on the coefficient for residing with same-sex parents $(\dot{\beta}-\tilde{\beta})$, but also on how much of the variation in school outcomes these observables can explain $(\tilde{R}-\dot{R})$. We 
bootstrap the standard errors using 1,000 replications. Ultimately, however, we are interested in the value of the selection ratio to explain away the result. If we find that the effect of unobservables would need to be several times larger than the effect of observables, this would suggest our findings likely have a causal interpretation, as we have included some of the most important variables that may induce selection bias. Nonetheless, this estimation assumes that selection on observables is informative about the selection on unobservables. The results should be interpreted bearing this in mind.

\section{Cousin Fixed Effects}

In a supplemental analysis, we also include cousin fixed effects. This is possible because our data allow us to link individuals across three generations. Thus, we compare children who share a grandmother/grandfather pair on the father's or mother's side, where the focal child has lived with same-sex parents and the cousins have not. Prior research has used this approach based on the rationale that cousins share some genetic material (Geronimus, Korenman, and Hillemeier 1994; Hällsten and Pfeffer 2017). A limitation of this approach, however, is that we need grandparents with multiple children and enough variation in the treatment. Therefore, the sample size is reduced, and the estimates are less precise. Moreover, although cousins share some genetic material, these children are still likely to be different in many ways. On average, first cousins have about one-eighth of their DNA in common, although this percentage may vary (Weir, Anderson, and Hepler 2006). As a result, selection on unobservables is potentially reduced, but not eliminated. These results are presented in Table S13 in the online supplement and lead to similar conclusions as the main results.

\section{RESULTS}

This section starts by describing the sample through a comparison of children raised by same-sex and different-sex parents on the main control variables. Then, we estimate how children raised by same-sex versus different-sex parents perform on the standardized test at the end of primary education. In addition, we present heterogeneous associations based on child's sex, ethnicity, and family structure. For the earlier cohorts, we estimate whether children with same-sex versus different-sex parents differ in diploma attainment in secondary education. Finally, we use treatment effect bounds to assess the causal interpretation of our findings.

\section{Sample Characteristics}

Table 1 presents descriptive statistics. Our data contain standardized test scores at the end of primary education for 1,204,692 children, from which 2,971 children (.25 percent) live with same-sex parents. Similar to prior work (Aldén et al. 2017; Boertien and Bernardi 2019; Watkins 2018), Table 1 shows that children with same-sex parents enjoy significantly higher socioeconomic status than do children with different-sex parents. Their parents are more likely to be older, to earn more, and to be well educated. Moreover, children with same-sex parents are more likely to have fewer siblings, and they are 4.5 percentage points less likely to have both parents born outside the Netherlands. This is likely due to the cumbersome procedures and high costs required to have children as a same-sex couple. However, children with same-sex parents are 23.6 percentage points less likely to be born into a married family than are children with different-sex parents. This is not surprising given that for some of the earlier cohorts, same-sex marriage was a novel concept people were not yet familiar with. If we solely consider children born after same-sex marriage was introduced in 2001, the difference in family structure between children with same-sex and different-sex parents is reduced but remains significant. Table 1 also suggests that a child with same-sex parents is equally likely to be a boy as is a child with different-sex parents. Finally, children who were raised by same-sex parents from birth enjoy even higher socioeconomic 
Table 1. Descriptive Statistics

\begin{tabular}{|c|c|c|c|}
\hline & $\begin{array}{c}\text { Children with } \\
\text { Different-Sex } \\
\text { Parents }\end{array}$ & $\begin{array}{l}\text { Children with } \\
\text { Same-Sex Parents } \\
\text { (Total) }\end{array}$ & $\begin{array}{c}\text { Children with } \\
\text { Same-Sex } \\
\text { Parents from Birth }\end{array}$ \\
\hline & (1) & (2) & (3) \\
\hline Sex ( 1 is boy, 0 is girl) & .501 & .493 & .499 \\
\hline \multicolumn{4}{|l|}{ Ethnicity } \\
\hline Both parents NL & .749 & $.698^{\#}$ & $.794^{\# \S}$ \\
\hline $\begin{array}{l}\text { One parent NL, other Western } \\
\text { country }\end{array}$ & .092 & $.120^{\#}$ & $.133^{\# \S}$ \\
\hline $\begin{array}{l}\text { One parent NL, other non-Western } \\
\text { country }\end{array}$ & .042 & $.108^{\#}$ & $.050^{\# \S}$ \\
\hline Both parents not NL & .118 & $.073^{\#}$ & $.023^{\# \S}$ \\
\hline Household annual net income in EUR & 79,300 & $86,128^{\#}$ & $90,779^{\# \S}$ \\
\hline $\begin{array}{l}\text { Parental education (1 is at least high } \\
\text { school degree) }\end{array}$ & .897 & $.931^{\#}$ & $.960^{\# \S}$ \\
\hline Average age of parents & 32.690 & $34.111^{\#}$ & $36.144^{\# \S}$ \\
\hline Family size & 1.875 & $1.602^{\#}$ & $1.534^{\# \S}$ \\
\hline \multicolumn{4}{|l|}{ Family structure } \\
\hline Married parents & .772 & $.536^{\#}$ & $.649^{\# \S}$ \\
\hline Cohabiting parents & .197 & $.298^{\#}$ & $.318^{\# \S}$ \\
\hline Other ${ }^{\mathrm{a}}$ & .031 & $.167^{\#}$ & $.032^{\S}$ \\
\hline Number of children & $1,201,721$ & 2,971 & 1,390 \\
\hline
\end{tabular}

${ }^{*}$ The coefficient is significantly different from the baseline coefficient of children with different-sex parents in column 1 at the 5 percent level using a two-tailed $z$ test for continuous variables and a twotailed test of proportions for categorical variables.

${ }^{\S}$ The coefficient is significantly different from the baseline coefficient of children with same-sex parents (total) in column 2 at the 5 percent level using a two-tailed $z$ test for continuous variables and a twotailed test of proportions for categorical variables.

aThis category includes children born into a family with one parent and a stepparent as well as adopted children and foster children.

status than both children with different-sex parents and the overall sample of children with same-sex parents.

In Table S17 in the online supplement, we describe socioeconomic characteristics of same-sex parents in more detail and compare them to same-sex couples without children, different-sex couples without children, and different-sex couples with children. Based on the proxies for socioeconomic status, we conclude that same-sex couples with children have the highest socioeconomic status among the four groups, followed by different-sex couples with and without children. Same-sex couples without children seem to have the lowest socioeconomic status. ${ }^{15}$ Therefore, selection on observables stems from two sources: same-sex couples with children have higher socioeconomic status than both the overall population and same-sex couples without children.

\section{Children with Same-Sex Parents and Achievement in Primary Education}

Table 2 compares standardized test scores, measured at the end of primary education, of children with same-sex versus different-sex parents. The first two columns include all children who resided with a same-sex couple for at least one year. This group includes children raised by same-sex parents from birth as well as children from previous different-sex relationships and adopted children. The reference group includes all children with different-sex parents. Column 1 shows that children with same-sex parents perform significantly better at the end of primary education than do their peers 
with different-sex parents. In particular, we find that children with same-sex parents have test scores .106 standard deviations higher than children with different-sex parents. In column 2, we control for socioeconomic variables. All the coefficients of the control variables have the expected signs. The results indicate that higher parental education and income, as well as older parents, increase children's academic performance. On the other hand, children in larger families and children whose parents are not married are likely to perform worse on the standardized test. We further find that children of foreign ethnicity have considerably lower achievement than do children of Dutch ethnicity, except when one parent is Dutch and the other parent is of Western ethnicity. Although boys appear to perform worse than girls, the coefficient is very close to zero.

Table 2 also includes indicators for neighborhood of residence as fixed effects in the regression to account for unobserved heterogeneity at the neighborhood level. Table S11 in the online supplement includes a randomeffects model to measure the size of neighborhood effects. The proportion of variance in the test scores accounted for by neighborhood is about 14 percent. More importantly, column 2 in Table 2 shows that once we control for socioeconomics variables, the estimated coefficient on same-sex parents drops by about half. This is consistent with the hypothesis that same-sex parents invest considerable resources into obtaining children in the first place, and therefore they have higher socioeconomic status than do different-sex parents, on average. Nonetheless, even after controlling for socioeconomic variables, at the end of primary education, children with same-sex parents still have test scores .054 standard deviations higher than their peers with different-sex parents, and that difference is statistically significant.

In the last three columns of Table 2, we only consider children who were raised by same-sex parents from birth. We exclude children from previous different-sex relationships and adopted (and foster) children, as parental separation and adoption may have negative independent effects on test scores, and therefore create selection bias (Rosenfeld 2010). ${ }^{16}$ The reference group includes all children raised by different-sex parents, except adopted children. ${ }^{17}$ Column 3 includes a specification without control variables, and column 4 includes a specification with control variables. Our preferred specification in column 4 shows that, if we only consider children raised by same-sex parents from birth, the coefficient increases significantly to .139 standard deviations, compared to the coefficient of .054 for all children with same-sex parents. To place this rather large estimate in perspective, in his synthesis of over 800 metaanalyses, Hattie (2009) finds that the average association of having a good teacher on student achievement is .32 standard deviations. The association we find of residing with samesex parents and student achievement is close to half the average teacher association.

Table S12 in the online supplement presents results from an additional specification in which we include the entire sample of children with same-sex parents but explicitly control for the number of family transitions and for adoption. The association amounts to .136 standard deviations and remains significant. Nonetheless, these control variables may be endogenous to residing with same-sex parents, as explained in the Control Variables section. Table S12 also presents results in which we compare children who began living with same-sex parents sometime after birth, with all children living with different-sex parents as the reference group. As expected from the negative influence of parental separation and adoption, the association including all control variables is negative (-.028 standard deviations), albeit not significant. However, once we compare the test scores of children who began living with same-sex parents sometime after birth with test scores of children living with different-sex parents who experienced at least one family transition as the reference group, the association is .009 standard deviations and insignificant.

As a final specification in column 5 of Table 2, we perform coarsened exact matching applied on control variables used in the 
Table 2. Children with Same-Sex Parents and Standardized Test Scores at the End of Primary Education

\begin{tabular}{|c|c|c|c|c|c|}
\hline & \multicolumn{2}{|c|}{ All Children } & \multicolumn{3}{|c|}{$\begin{array}{l}\text { Children Raised by Same-Sex } \\
\text { Parents from Birth }{ }^{\mathrm{a}}\end{array}$} \\
\hline & (1) & $(2)$ & (3) & (4) & (5) \\
\hline $\begin{array}{l}\text { Child has same-sex parents ( } 1 \text { is } \\
\text { yes) }\end{array}$ & $\begin{array}{l}.106^{* * *} \\
(.019)\end{array}$ & $\begin{array}{l}.054^{* *} \\
(.018)\end{array}$ & $\begin{array}{l}.194^{* * *} \\
(.024)\end{array}$ & $\begin{array}{l}.139^{* * *} \\
(.023)\end{array}$ & $\begin{array}{l}.147^{* * *} \\
(.041)\end{array}$ \\
\hline Sex (1 is male) & $\begin{array}{l}-.004^{*} \\
(.002)\end{array}$ & $\begin{array}{l}-.009^{* * *} \\
(.002)\end{array}$ & $\begin{array}{l}-.003 \\
(.002)\end{array}$ & $\begin{array}{l}-.007^{* * *} \\
(.002)\end{array}$ & \\
\hline \multicolumn{6}{|l|}{ Ethnicity (ref: both parents born in NL) } \\
\hline $\begin{array}{l}\text { One parent NL, other Western } \\
\text { country }\end{array}$ & & $\begin{array}{l}.004 \\
(.003)\end{array}$ & & $\begin{array}{l}.004 \\
(.003)\end{array}$ & \\
\hline $\begin{array}{l}\text { One parent NL, other non- } \\
\text { Western country }\end{array}$ & & $\begin{array}{l}-.031^{* * *} \\
(.005)\end{array}$ & & $\begin{array}{l}-.031^{* * *} \\
(.005)\end{array}$ & \\
\hline Both parents not NL & & $\begin{array}{l}-.111^{* * *} \\
(.006)\end{array}$ & & $\begin{array}{l}-.111^{* * *} \\
(.006)\end{array}$ & \\
\hline Parental education (1 is diploma SE) & & $\begin{array}{l}.531^{* * *} \\
(.004)\end{array}$ & & $\begin{array}{l}.532^{* * *} \\
(.004)\end{array}$ & \\
\hline Log household income & & $\begin{array}{l}.083^{* * *} \\
(.002)\end{array}$ & & $\begin{array}{l}.084^{* * *} \\
(.002)\end{array}$ & \\
\hline Mean parental age & & $\begin{array}{l}.018^{* * *} \\
(.000)\end{array}$ & & $\begin{array}{l}.018^{* * *} \\
(.000)\end{array}$ & \\
\hline Family size & & $\begin{array}{l}-.066^{* * *} \\
(.001)\end{array}$ & & $\begin{array}{l}-.066^{* * *} \\
(.001)\end{array}$ & \\
\hline \multicolumn{6}{|l|}{ Family structure (ref: married parents) } \\
\hline Cohabiting parents & & $\begin{array}{l}-.073^{* * *} \\
(.002)\end{array}$ & & $\begin{array}{l}-.073^{* * *} \\
(.002)\end{array}$ & \\
\hline Other & & $\begin{array}{l}-.367^{* * *} \\
(.012)\end{array}$ & & $\begin{array}{l}-.154^{* * *} \\
(.032)\end{array}$ & \\
\hline \multicolumn{6}{|l|}{ Fixed effects } \\
\hline Birth year & Yes & Yes & Yes & Yes & \\
\hline Neighborhood & No & Yes & No & Yes & \\
\hline Method & OLS & OLS & OLS & OLS & $\mathrm{CEM}^{\mathrm{b}}$ \\
\hline Number of children & $1,204,692$ & $1,204,692$ & $1,195,624$ & $1,195,624$ & 48,388 \\
\hline $\begin{array}{l}\text { Number of children with same-sex } \\
\text { parents }\end{array}$ & 2,971 & 2,971 & 1,390 & 1,390 & 1,390 \\
\hline$R^{2}$ & .004 & .108 & .004 & .109 & .121 \\
\hline
\end{tabular}

Note: Standard errors clustered at the neighborhood level are in parentheses. The outcome is standardized test score measured at the end of primary education. Household income, parental age, family size, family structure, and neighborhood are measured at birth.

aThis means children from previous different-sex relationships and adopted children (including foster children) are excluded.

${ }^{\mathrm{b}} \mathrm{CEM}$ stands for coarsened exact matching (see Matching Analysis section).

${ }^{*} p<.05 ;{ }^{* *} p<.01 ;{ }^{* * *} p<.001$ (two-tailed $t$-tests).

previous specification. For every child living with same-sex parents, this technique selects a corresponding child living with differentsex parents having either the exact same values or similar coarsened values on observed characteristics, so CEM is able to account for the much larger group of children with different-sex versus same-sex parents. As a result, $\mathrm{CEM}$ can reduce both the imbalance in covariates and the model dependence (Blackwell et al. 2009; Iacus et al. 2012). Despite the alternative specification in which we compare 
Table 3. Children Raised by Same-Sex Parents from Birth and Standardized Test Scores at the End of Primary Education by Sex, Ethnicity, and Family Structure

\begin{tabular}{|c|c|c|c|c|c|c|}
\hline & Boys & Girls & Foreign $^{a}$ & Dutch & Married & Cohabiting \\
\hline & (1) & (2) & (3) & (4) & (5) & (6) \\
\hline $\begin{array}{l}\text { Child has same-sex parents } \\
\text { ( } 1 \text { is yes) }\end{array}$ & $\begin{array}{l}.155^{* * *} \\
(.033)\end{array}$ & $\begin{array}{l}.126^{* * *} \\
(.033)\end{array}$ & $\begin{array}{l}.206 * * * \\
(.057)\end{array}$ & $\begin{array}{l}.115^{* * * *} \\
(.026)\end{array}$ & $\begin{array}{l}.122^{* * *} \\
(.029)\end{array}$ & $\begin{array}{l}.144^{* * *} \\
(.043)\end{array}$ \\
\hline Number of children & 599,676 & 595,948 & 301,244 & 894,380 & 928,965 & 265,637 \\
\hline $\begin{array}{l}\text { Number of children with } \\
\text { same-sex parents }\end{array}$ & 696 & 694 & 286 & 1,104 & 902 & 442 \\
\hline$R^{2}$ & .115 & .124 & .166 & .096 & .109 & .156 \\
\hline
\end{tabular}

Note: Standard errors clustered at the neighborhood level are in parentheses. The outcome is standardized test score measured at the end of primary education. All models have been estimated using OLS with additional controls included. These controls are sex, ethnicity, birth year, parental education, household income at birth, neighborhood at birth, average age of parents at birth, family size at birth, and family structure at birth.

a"Foreign" is defined as at least one parent not born in the Netherlands; "Dutch" is defined as both parents born in the Netherlands.

$* * * p<.001$ (two-tailed $t$-tests).

children with similar observed characteristics, the estimated coefficient in column 5 is slightly higher (although not significantly lower) at .147 standard deviations than the coefficient in column 4 using OLS. This similarity in the estimates obtained by CEM and OLS yields more confidence in our main results.

\section{Heterogeneity by Sex, Ethnicity, and Family Structure}

In Table 3, we perform the analysis by child's sex and ethnicity as well as family structure. In Table S14 in the online supplement, we also estimate our models by neighborhood of residence. Specifically, we defined neighborhoods that included more than 1,500 addresses per squared kilometer as urban, and other neighborhoods are defined as rural. We found almost identical coefficients that are similar to the main results. Therefore, we present results by child's sex, ethnicity, and family structure, for which potential heterogeneous associations have been found in prior work (Allen 2013; Sullins 2015b; Watkins 2018). To conserve space, we only present the coefficient of the treatment variable. Each model was estimated while controlling for covariates as in Table 2. Allen (2013) found that girls, rather than boys, are more negatively affected by residing with same-sex parents. The results in columns 1 and 2 do not support this finding. Although the positive association is slightly higher for boys than for girls, a test of equality of coefficients does not reject the null hypothesis of equal coefficients $(p=.370)$.

We also split the sample by ethnicity. Among children with same-sex parents, children whose parents were born outside the Netherlands may experience more stigma than children whose parents are native-born. However, in our sample of children who were raised by same-sex parents from birth, only 32 had both parents who were foreign-born, and among these, only 10 children had parents who were both born in a non-Western country. Thus, among minority populations in the Netherlands, same-sex couples with children appear to be rare. Therefore, to maximize sample size, we redefine the categorical ethnicity indicator and split the sample into children with at least one parent born outside the Netherlands, and children whose parents were both native-born. We find that children with same-sex parents of both foreign and Dutch ethnicity perform better on standardized tests than do children with different-sex parents. The coefficient for foreign ethnicity children, shown in column 3 , is higher than 
Table 4. Bounding the Causal Effect of Being Raised by Same-Sex Parents from Birth on Standardized Test Scores at the End of Primary Education

\begin{tabular}{|c|c|c|c|c|}
\hline \multirow[t]{2}{*}{ Selection ratio ${ }^{a}$} & 1 & 1.5 & 2 & 3.19 \\
\hline & (1) & $(2)$ & (3) & $(4)$ \\
\hline Child has same-sex parents ( 1 is yes) & $\begin{array}{l}.119^{* * *} \\
(.015)\end{array}$ & $\begin{array}{l}.093^{* * *} \\
(.016)\end{array}$ & $\begin{array}{l}.070^{* * *} \\
(.016)\end{array}$ & $\begin{array}{l}.044 \\
(.038)\end{array}$ \\
\hline Number of children & $1,195,624$ & $1,195,624$ & $1,195,624$ & $1,195,624$ \\
\hline Number of children with same-sex parents & 1,390 & 1,390 & 1,390 & 1,390 \\
\hline
\end{tabular}

Note: Bootstrapped standard errors are in parentheses (1,000 replications). The outcome is standardized test score measured at the end of primary education. $R^{2}$ max is set at 1.3 times $R^{2}$ from the regression including all controls as recommended by Oster (2019). The table shows a bounding analysis for children raised by same-sex parents from birth (children from previous different-sex relationships and adopted children are excluded). The results show that selection on unobservables, such as ability and parental motivation, would need to be 3.19 times higher than selection on observables (all control variables used in the main analysis: sex, ethnicity, birth year, parental education, household income at birth, neighborhood at birth, average age of parents at birth, family size at birth, and family structure at birth) to render insignificant the influence of being raised by same-sex parents on standardized test scores at the end of primary education.

${ }^{a}$ For instance, a selection ratio of 2 indicates that when the selection on unobserved characteristics is two times higher than the selection on observed characteristics, the association between being raised by same-sex parents and standardized test scores at the end of primary education is .070 and significant at the .001 percent level.

$* * * p<.001$ (two-tailed $t$-tests).

the coefficient for Dutch children in column 4 , but so is the standard error due to a smaller sample size. A test of equality of coefficients does not reject the null hypothesis of equal coefficients $(p=.344)$.

Finally, we split the sample by family structure. Watkins (2018) estimated that children with same-sex parents progress through school faster if the couple is married rather than cohabiting. Sullins (2015b), on the other hand, argued that children with same-sex parents perform worse on grade point average (GPA) if the couple is married rather than cohabiting. We find that children with same-sex parents outperform children with different-sex parents by .122 standard deviations if both the samesex and different-sex couple are married, and by .144 standard deviations if both the samesex and different-sex couple are cohabiting. However, these coefficients are not significantly different from each other $(p=.526)$.

\section{Bounding the Causal Effect}

We have shown that children with same-sex parents are likely to outperform children with different-sex parents on standardized tests at the end of primary education. This result, however, is an association and not a causal effect. Table 2 suggested that selection plays a role when comparing test scores of children with same-sex versus different-sex parents. Once we controlled for socioeconomic variables, the positive coefficient dropped significantly. Moreover, selection on unobservable characteristics such as ability and parental motivation may also be present. Therefore, we would expect our results to represent an upper bound of the causal effect of being raised by same-sex parents.

To better understand these selection effects, we perform Oster's (2019) bounding approach. This approach exploits coefficient and $R^{2}$ movements before and after the inclusion of observed characteristics to bound the treatment effect. Column 3 in Table 4 indicates that even when the selection on unobserved characteristics is twice as high as selection on observed characteristics, children with same-sex parents outperform children with different-sex parents by .07 standard deviations. Column 4 shows that the selection on unobserved characteristics would have to be at least 3.19 times higher than the selection 
on observed characteristics already included in the model to render our estimate insignificant. Although it is possible that unobserved characteristics such as parental motivation and family planning before having children could exercise a considerable influence on the results, we do include several of the main observable characteristics, such as parental education, origin, age, and income, as well as a variable for a child's neighborhood. These variables are likely to be correlated with parental motivation (Guryan, Hurst, and Kearney 2008). Nevertheless, it is important to note that this bounding method assumes that selection on observed characteristics is informative about selection on unobserved characteristics. Moreover, the bounding analysis is dependent on the choice of $R_{\max }$, which is set at 1.3 times $R^{2}$ from the regression including all controls as recommended by Oster (2019). Although our results are robust to using a higher value of $R_{\max }$ set to .218 (see Table S15 in the online supplement), in the absence of studies that used this type of analysis in a similar context, it is unclear how large $R_{\max }$ should be.

\section{Children with Same-Sex Parents and Diploma Attainment in Secondary Education}

Table 5 compares children with same-sex versus different-sex parents on diploma attainment in secondary education. Children in our sample were born between 1998 and 2007 , so we can only analyze children from earlier cohorts (1998 to 2001), as they alone are old enough to have graduated from secondary education. The first two columns include all children who resided with samesex parents at least once. Columns 1 and 2 show that children with same-sex parents perform just as well on diploma attainment as their peers with different-sex parents. However, once we consider children who were actually raised by same-sex parents from birth in column 4 , children with same-sex parents are 4.8 percentage points more likely to graduate than are children with differentsex parents (from a mean diploma attainment of children with different-sex parents of 92 percent). CEM confirms these results, although the coefficient is slightly lower at 3.8 percentage points. In summary, children raised by same-sex parents from birth continue to outperform their peers raised by different-sex parents in secondary education. Nonetheless, as we only observe 280 children with same-sex parents in our preferred specification in column 4, and most of these children were born before legalization of same-sex marriage in 2001, these results should be interpreted with caution.

\section{DISCUSSION}

Using a unique administrative longitudinal dataset from the Netherlands, this article compared children with same-sex versus different-sex parents on high-stakes standardized test scores at the end of primary education. The results indicated that children raised by same-sex parents from birth outperformed children with different-sex parents by .139 standard deviations on these tests. We also found that in secondary education, children with same-sex parents continued to outperform children with different-sex parents. Our results suggest that children raised by samesex parents from birth are 4.8 percentage points more likely to graduate than children with different-sex parents. These results do not appear to be moderated by child's sex, ethnicity, or family structure.

Overall, these results contrast with earlier studies using cross-sectional census data. Prior work found either a negative association between residing with same-sex parents and school outcomes (Allen 2013; Allen et al. 2013) or no association at all (Boertien and Bernardi 2019; Rosenfeld 2010; Watkins 2018). We attribute this difference to the cross-sectional nature of the census data and to the Dutch institutional context. First, due to the cross-sectional nature of census data, it was not possible to differentiate between children raised by same-sex parents from birth and children who happened to live with samesex parents at one point in time. Our results are in line with Aldén and colleagues (2017), 
Table 5. Children with Same-Sex Parents and Diploma Attainment

\begin{tabular}{|c|c|c|c|c|c|}
\hline & \multicolumn{2}{|c|}{ All Children } & \multicolumn{3}{|c|}{$\begin{array}{l}\text { Children Raised by Same-Sex } \\
\text { Parents from Birth }{ }^{\mathrm{c}}\end{array}$} \\
\hline & (1) & $(2)$ & (3) & (4) & (5) \\
\hline Child has same-sex parents ( 1 is yes) & $\begin{array}{l}-.007 \\
(.010)\end{array}$ & $\begin{array}{l}.010 \\
(.010)\end{array}$ & $\begin{array}{l}.040^{* * *} \\
(.011)\end{array}$ & $\begin{array}{l}.048^{* * *} \\
(.010)\end{array}$ & $\begin{array}{l}.038^{*} \\
(.016)\end{array}$ \\
\hline Additional controls ${ }^{\mathrm{a}}$ & No & Yes & No & Yes & Yes \\
\hline Method $^{b}$ & LPM & LPM & LPM & LPM & CEM \\
\hline Number of children & 395,322 & 395,322 & 392,251 & 392,251 & 22,199 \\
\hline Number of children with same-sex parents & 764 & 764 & 280 & 280 & 280 \\
\hline$R^{2}$ & .002 & .043 & .002 & .043 & .061 \\
\hline
\end{tabular}

Note: Standard errors clustered at the neighborhood level are in parentheses. The outcome diploma attainment is coded as an indicator given a value of 1 if the child graduated from upper-secondary education, and 0 if the child dropped out before graduating.

additional controls include sex, ethnicity, birth year, parental education, household income at birth, neighborhood at birth, average age of parents at birth, family size at birth, and family structure at birth. bLPM stands for linear probability model; CEM stands for coarsened exact matching (see Methods section).

'This means children from previous different-sex relationships and adopted children (including foster children) are excluded.

${ }^{*} p<.05 ; * * * p<.001$ (two-tailed $t$-tests).

the only other study to have used administrative data, although Aldén and colleagues include only a limited sample of 56 children with lesbian parents. Second, country differences are related to substantial differences in findings in the literature (Schumm 2018). Our study pertains to the Netherlands, which has a more supportive cultural and legal context for same-sex parents than do most other countries (De Witte, Iterbeke, and Holz 2019). For instance, in a poll of the European Union adult population in 2015, the Netherlands scored second highest on all measures, with only Sweden having a more positive attitude toward same-sex couples (European Commission 2015). Among Dutch participants, 96 percent agreed that gay persons should have the same rights as heterosexual persons. Moreover, 86 percent of respondents would have been comfortable with their son or daughter having a relationship with someone of the same sex. Furthermore, our data show that in the Netherlands, almost half of the children living with same-sex parents were raised by a same-sex couple from birth. The results are likely to differ in other national settings.
It is also possible to address some of the theoretical mechanisms that may be driving our results. We found that children with samesex parents perform better in school than children with different-sex parents, so neither the specialization theory nor the kin selection theory were supported by the data. Our results mostly support the hypothesis that given the time-consuming and costly procedures for same-sex couples to obtain children, same-sex parents typically have higher socioeconomic status, resulting in better school outcomes. Indeed, once we controlled for socioeconomic variables, the positive association between residing with same-sex parents and test scores dropped significantly. Nonetheless, the positive association was not entirely removed. By contrast, when we consider solely children who live with same-sex parents but were born into different-sex relationships, they tend to perform worse than children living with different-sex parents, albeit not significantly. We used a bounding analysis to analyze the causal effect of living with same-sex parents. Treatment effect bounds indicated that the selection on unobserved characteristics would 
have to be more than three times higher than the selection on observed characteristics to reduce the positive association to zero. Although this is possible, the observed characteristics were chosen to reflect the most important controls found in prior work. For instance, same-sex parents may have had higher a priori motivation to become parents that we do not observe, but parental motivation is highly correlated with education (Guryan et al. 2008) and this is included in our models.

The compensation theory provides one possible explanation for our results - it states that same-sex parents might compensate for their unique stressors by investing more time and energy into their children. We can partially test this theory by separating the sample into two periods: before and after legalization of same-sex marriage in 2001. If compensation theory drives parental behavior, we would expect the association to remain unchanged or lessen after legalization of same-sex marriage, as same-sex parents would have less incentive to increase their parental effort in response to societal barriers. These results are presented in Table S16 in the online supplement. We find an association of .232 standard deviations before 2001, and an association of .124 standard deviations after 2001. Thus, we do indeed find a higher coefficient before legalization of same-sex marriage, and the difference is significant at the 5 percent level $(p=.019)$. This provides some suggestive evidence for the compensation theory. Nonetheless, our data do not include a measure on parental investment to investigate this further. For instance, we cannot test whether same-sex parents spend more time with their children than do different-sex parents. Prickett and colleagues' (2015) study suggests this may be the case.

Although we attempted to solve the main caveats in the research on outcomes for children with same-sex parents, this study is not without limitations. First, our administrative data do not include a measure of sexual orientation. Second, we solely considered couples and made no claims about children living with single-parents. Third, our sample of children with gay male parents is too small to draw conclusions about heterogeneous associations by the sex of same-sex parents. This may be better addressed by studies using census data (Boertien and Bernardi 2019; Watkins 2018), although these studies suffer from the important limitation of observing just a cross-sectional snapshot. In addition, we could estimate diploma attainment only for earlier cohorts, leading to a relatively small sample size of children with same-sex parents. Finally, qualitative analyses should accompany these administrative findings to explore potential mechanisms in detail. Further research should continue refining the insights from these administrative findings, census findings, and qualitative findings.

\section{Acknowledgments}

For their helpful comments and suggestions, we would like to thank Omar Lizardo, Rory McVeigh, Michael Rosenfeld, Walter Schumm, Paul Sullins, Douglas Allen, Hui Liu, Corinne Reczek, Seth Sanders, Anders Björklund, Lina Aldén, Mats Hammarstedt, Gunnar Andersson, Marie Evertsson, Martin Kolk, Silvia Palmaccio, Sunčica Vujić, Wim Groot, Dieter Verhaest, Erwin Ooghe, Daniel Horn, Christiaan Monden, participants of the University of Oxford Department of Sociology reading group, and participants of the conferences of the American Economic Association, the American Sociological Association, the Population Association of America, the Royal Economic Society, the European Society for Population Economics, the European Association of Labour Economists, and the Society of Economics of the Household, as well as seminar and workshop participants at Stanford University, Maastricht University, KU Leuven, Hungarian Academy of Sciences, and Université Libre de Bruxelles.

\section{Funding}

The project leading to this research received funding from the European Union's Horizon 2020 research and innovation programme [grant number 691676] and the Research Foundation Flanders [grant number G067120N]. Deni Mazrekaj acknowledges funding by the Research Foundation Flanders (FWO) as Aspirant [grant number 1172519N] and by the European Research Council [grant number 681546: FAMSIZEMATTERS]. The authors declare that they have no relevant or material financial interests that relate to the research described in this article.

\section{Data Note}

The data for this study are protected by a confidentiality agreement and we are precluded from sharing the data with others. Interested readers can consult the online 
supplement for information on how to obtain access to the data. We would be happy to provide assistance and Stata code to replicate the results of this study.

\section{ORCID iDs}

Deni Mazrekaj (iD https://orcid.org/0000-0002-3311-6056

Sofie Cabus iD https://orcid.org/0000-0001-6719-5824

\section{Notes}

1. We use the term "parental separation" to refer to divorce for married couples as well as couples in a registered partnership, and to refer to dissolution for cohabiting couples.

2. For instance, the 2000 U.S. Census does not provide information on the exact grade attended, but groups students into two groups: grades 1 to 4 in one category and grades 5 to 8 in the other. This introduces a measurement error when constructing the progress through school variable. Although the recent ACS data provide more detailed information, it is difficult to account for academic redshirting, where parents may purposefully delay their child's entry into school to increase the child's school readiness (Boertien and Bernardi 2019).

3. This assumes neither parent had a prior sex reassignment surgery, and that gay men did not participate in a surrogacy in which both partners donated genetic material.

4. Lesbian women can use medically assisted insemination or in vitro fertilization techniques (IVF), and gay men can use surrogacy.

5. Although different-sex couples can get reimbursed by insurance for IVF in the Netherlands, this is not necessarily the case for lesbian couples and single women, as the absence of a male partner may not count as a medical issue, depending on the situation at hand.

6. We could find a match for about 93 percent of the population, as some of the parental identifiers, partner identifiers, and addresses were missing.

7. By adoption, we mean same-sex couples adopting a child who was conceived by another couple, and not second-parent adoptions in which, for instance, the female partner of the birth mother (also called the social mother) becomes a legal mother through adoption.

8. Ideally, we would like to compare school outcomes of adopted children of same-sex versus differentsex parents. However, the sample of adopted children of same-sex parents is too small to come to a meaningful conclusion. Nonetheless, it is reassuring that results of this analysis lead to a similar conclusion as the main results, although the coefficients lose significance due to low statistical power (see Table S4 in the online supplement).

9. Note that it is possible for children to repeat a grade and therefore take the test at a later age. This would introduce a mechanical relationship between the number of years observed in the data and the probability of residing with same-sex parents. The longer a child is observed in the data (e.g., a child who needed seven years of primary education to take the test versus a child who needed 10 years of primary education to take the test), the higher the probability a child could reside with same-sex parents. Therefore, we observe each child until they are 12 years old. Nonetheless, observing children until the actual age at which they took the test does not influence our results.

10. Using a dummy variable for parental education may lead to inflated coefficients for children with samesex parents, as these parents may be more educated. Unfortunately, our data do not offer a further refinement of the parental education variable for the full sample. Nonetheless, we constructed a categorical variable for most of the sample (82.41 percent) as follows: (1) at least one parent is a high school dropout; (2) both parents finished secondary education, but not higher education; (3) at least one parent obtained a bachelor's degree; (4) at least one parent obtained a master's degree; and (5) at least one parent obtained a $\mathrm{PhD}$. These results lead to the same conclusion as the main results and are presented in Table S7 in the online supplement.

11. Note that we cannot distinguish between more complex forms of parenting, such as three-way parenting (e.g., two mothers and a father who are raising a child together).

12. This means that for diploma attainment, we estimate a linear probability model (LPM) for ease of interpretation and for comparison with the results obtained by coarsened exact matching. Results from a logit model are presented in Table S10 in the online supplement and are very similar to the LPM results.

13. Indicators for neighborhood of residence are included as fixed effects. We also performed a random-effects model to quantify the size of the neighborhood effects (see Table S11 in the online supplement).

14. In Table S15 in the online supplement, we experiment with a higher value of $R_{\max }$. Namely, we set $R_{\max }$ equal to .218 , double the $R^{2}$ in the controlled regression. Although the selection ratio is reduced, the main conclusions remain similar.

15. This conclusion holds if we consider lesbian and gay male couples separately. Gay male couples with children have the highest socioeconomic status, followed by lesbian couples with children, differentsex couples with children, different-sex couples without children, and gay male couples without children. Lesbian couples without children have the lowest socioeconomic status.

16. Note that the family structure category "other" now includes solely stepfamilies, as adopted and foster children have been excluded from the analyses. 
17. Regression results comparing test scores between adopted children with same-sex versus differentsex parents are presented in Table S4 in the online supplement. We find that adopted children with same-sex parents perform better on the test than do adopted children with different-sex parents by .059 standard deviations, although this coefficient is not significant at the 5 percent level. This is likely due to a very small sample size of adopted children with same-sex parents (50 children).

\section{References}

Aldén, Lina, Anders Björklund, and Mats Hammarstedt. 2017. "Early Health and School Outcomes for Children with Lesbian Parents: Evidence from Sweden." IZA Discussion Paper No. 10616.

Allen, Douglas W. 2013. "High School Graduation Rates among Children of Same-Sex Households." Review of Economics of the Household 11(4):635-58.

Allen, Douglas W. 2015. "More Heat Than Light: A Critical Assessment of the Same-Sex Parenting Literature, 1995-2013." Marriage \& Family Review 51(2):154-82.

Allen, Douglas W., Catherine Pakaluk, and Joseph Price. 2013. "Nontraditional Families and Childhood Progress through School: A Comment on Rosenfeld." Demography 50(3):955-61.

Allen, Douglas W., Catherine Pakaluk, and Joseph Price. 2014. "Normal Progress through School: Further Results." In No Differences? How Children in SameSex Households Fare: Studies from Social Science, edited by A. Samuel. Princeton, NJ: Witherspoon Institute.

Altonji, Joseph G., Todd E. Elder, and Christopher R. Taber. 2005. "Selection on Observed and Unobserved Variables: Assessing the Effectiveness of Catholic Schools." Journal of Political Economy 113(1):151-84. Angrist, Joshua D., and Jörn-Steffen Pischke. 2009. Mostly Harmless Econometrics: An Empiricist's Companion. Princeton, NJ: Princeton University Press.

Bell, Ann V. 2019. “"Trying to Have Your Own First; It's What You Do': The Relationship between Adoption and Medicalized Infertility." Qualitative Sociology 42(2):479-98.

Biblarz, Timothy J., and Judith Stacey. 2010. "How Does the Gender of Parents Matter?" Journal of Marriage and Family 72(1):3-22.

Black, Dan A., Gary Gates, Seth G. Sanders, and Lowell J. Taylor. 2002. "Why Do Gay Men Live in San Francisco?" Journal of Urban Economics 51(1):53-70.

Black, Dan A., Seth G. Sanders, and Lowell J. Taylor. 2007. "The Economics of Lesbian and Gay Families." Journal of Economic Perspectives 21(2):53-70.

Blackwell, Matthew, Stefano Iacus, Gary King, and Giuseppe Porro. 2009. "CEM: Coarsened Exact Matching in Stata." Stata Journal 9(4):524-46.

Boertien, Diederik, and Fabrizio Bernardi. 2019. "SameSex Parents and Children's School Progress: An Association That Disappeared over Time." Demography 56(2):477-501.
Bos, Henny M. W., Frank van Balen, Dymph Van den Boom, and Theodorus G. M. Sandfort. 2004. "Minority Stress, Experience of Parenthood and Child Adjustment in Lesbian Families." Journal of Reproductive and Infant Psychology 22(4):291-304.

Cenegy, Laura F., Justin T. Denney, and Rachel T. Kimbro. 2018. "Family Diversity and Child Health: Where Do Same-Sex Couple Families Fit?" Journal of Marriage and Family 80(1):198-218.

Cheng, Simon, and Brian Powell. 2015. "Measurement, Methods, and Divergent Patterns: Reassessing the Effects of Same-Sex Parents." Social Science Research 52:615-26.

Cunha, Flavio, and James Heckman. 2007. "The Technology of Skill Formation." AEA Papers and Proceedings 97(2):31-47.

Cunha, Flavio, James J. Heckman, and Susanne M. Schennach. 2010. "Estimating the Technology of Cognitive and Noncognitive Skill Formation." Econometrica 78(3):883-931.

De Witte, Kristof, Kaat Iterbeke, and Oliver Holz. 2019. “Teachers' and Pupils' Perspectives on Homosexuality: A Comparative Analysis across European Countries.” International Sociology 34(4):471-519.

Diaz-Serrano, Luis, and Enric Meix-Llop. 2016. "Do Schools Discriminate against Homosexual Parents? Evidence from a Randomized Correspondence Experiment." Economics of Education Review 53:133-42.

Doyle, Joseph J. Jr. 2007. "Child Protection and Child Outcomes: Measuring the Effects of Foster Care." American Economic Review 97(5):1583-610.

Elwert, Felix, and Christopher Winship. 2014. "Endogenous Selection Bias: The Problem of Conditioning on a Collider Variable." Annual Review of Sociology 40:31-53.

European Commission. 2015. "Special Eurobarometer 437: Discrimination in the EU in 2015." Brussels: European Commission.

Fedewa, Alicia L., and Teresa P. Clark. 2009. "Parent Practices and Home-School Partnerships: A Differential Effect for Children with Same-Sex Coupled Parents?" Journal of GLBT Family Studies 5(4):716-43.

Font, Sarah A., Lawrence M. Berger, Maria Cancian, and Jennifer L. Noyes. 2018. "Permanency and the Educational and Economic Attainment of Former Foster Children in Early Adulthood." American Sociological Review 83(4):716-43.

Gartrell, Nanette, and Henny Bos. 2010. "US National Longitudinal Lesbian Family Study: Psychological Adjustment of 17-Year-Old Adolescents.” Pediatrics 126(1):28-36.

Geronimus, Arline T., Sanders Korenman, and Marianne M. Hillemeier. 1994. "Does Young Maternal Age Adversely Affect Child Development? Evidence from Cousin Comparisons in the United States." Population and Development Review 20(3):585-609.

Golombok, Susan, Fiona Tasker, and Clare Murray. 1997. "Children Raised in Fatherless Families from Infancy: Family Relationships and the Socioemotional Development of Children of Lesbian and Single 
Heterosexual Mothers." Journal of Child Psychology and Psychiatry 38(7):783-91.

Guryan, Jonathan, Erik Hurst, and Melissa Kearney. 2008. "Parental Education and Parental Time with Children." Journal of Economic Perspectives 22(3):23-46.

Hällsten, Martin, and Fabian T. Pfeffer. 2017. “Grand Advantage: Family Wealth and Grandchildren's Educational Achievement in Sweden." American Sociological Review 82(2):328-60.

Hamilton, Laura, Simon Cheng, and Brian Powell. 2007. "Adoptive Parents, Adaptive Parents: Evaluating the Importance of Biological Ties for Parental Investment." American Sociological Review 72(1):95-116.

Hamilton, William D. 1964. "The Genetical Evolution of Social Behaviour." Journal of Theoretical Biology $7(1): 1-16$.

Hattie, John. 2009. Visible Learning: A Synthesis of over 800 Meta-analyses Relating to Achievement. New York: Routledge.

Heckman, James J. 2006. "Skill Formation and the Economics of Investing in Disadvantaged Children." Science 312(5782):1900-1902.

Herd, Pamela, Jeremy Freese, Kamil Sicinski, Benjamin W. Domingue, Kathleen Mullan Harris, Caiping Wei, and Robert M. Hauser. 2019. "Genes, Gender Inequality, and Educational Attainment." American Sociological Review 84(6):1069-98.

Ho, Daniel E., Kosuke Imai, Gary King, and Elizabeth A. Stuart. 2007. "Matching as Nonparametric Preprocessing for Reducing Model Dependence in Parametric Causal Inference." Political Analysis 15(3):199-236.

Iacus, Stefano M., Garry King, and Giuseppe Porro. 2012. "Causal Inference without Balance Checking: Coarsened Exact Matching." Political Analysis 20(1):1-24.

Kalmijn, Matthijs, Anneke Loeve, and Dorien Manting. 2007. "Income Dynamics in Couples and the Dissolution of Marriage and Cohabitation." Demography 44(1):159-79.

Kolk, Martin, and Gunnar Andersson. 2020. "Two Decades of Same-Sex Marriage in Sweden: A Demographic Account of Developments in Marriage, Childbearing, and Divorce." Demography 57:147-69.

Kreider, Rose M, and Daphne A. Lofquist. 2015. "Matching Survey Data with Administrative Records to Evaluate Reports of Same-Sex Married Couple Households." U.S. Census Bureau, Washington, DC, Working Paper SEHSD-WP2014-36.

MacCallum, Fiona, and Susan Golombok. 2004. "Children Raised in Fatherless Families from Infancy: A Follow-up of Children of Lesbian and Single Heterosexual Mothers at Early Adolescence." Journal of Child Psychology and Psychiatry 45(8):1407-19.

Manning, Wendy D., Marshal Neal Fettro, and Esther Lamidi. 2014. "Child Well-Being in Same-Sex Parent Families: Review of Research Prepared for American Sociological Association Amicus Brief." Population Research Policy Review 33:485-502.
McLanahan, Sara, Laura Tach, and Daniel Schneider. 2013. "The Causal Effects of Father Absence." Annual Review of Sociology 39:399-427.

McVeigh, Rory, and Maria-Elena D. Diaz. 2009. "Voting to Ban Same-Sex Marriage: Interests, Values, and Communities." American Sociological Review 74(6):891-915.

Obergefell v. Hodges. 2015. 14-556 (Supreme Court of the United States, June 26).

O'Connell, Martin, and Sarah Feliz. 2011. "Same-Sex Couple Household Statistics from the 2010 Census.” U.S. Census Bureau, Washington, DC, Working Paper SEHSD-WP2011-26.

Oster, Emily. 2019. "Unobservable Selection and Coefficient Stability: Theory and Evidence." Journal of Business \& Economic Statistics 37(2):1-18.

Perrin, Ellen C., Sean M. Hurley, Kathryn Mattern, Lila Flavin, and Ellen E. Pinderhughes. 2019. "Barriers and Stigma Experienced by Gay Fathers and Their Children." Pediatrics 143(2):1-9.

Pew Research Center. 2019, May 14. "Attitudes on SameSex Marriage.” Retrieved March 17, 2020 (https:// www.pewforum.org/fact-sheet/changing-attitudeson-gay-marriage).

Potter, Daniel. 2012. "Same-Sex Parent Families and Children's Academic Achievement." Journal of Marriage and Family 74(3):556-71.

Prickett, Kate C., Alexa Martin-Storey, and Robert Crosnoe. 2015. "A Research Note on Time with Children in Different- and Same-Sex Two-Parent Families." Demography 52(3):905-18.

Reczek, Corinne, Russell Spiker, Hui Liu, and Robert Crosnoe. 2016. "Family Structure and Child Health: Does the Sex Composition of Parents Matter?" Demography 53(5):1605-30.

Reczek, Corinne, Russell Spiker, Hui Liu, and Robert Crosnoe. 2017. "The Promise and Perils of Population Research on Same-Sex Families." Demography 54(6):2385-97.

Regnerus, Mark. 2012. "How Different Are the Adult Children of Parents Who Have Same-Sex Relationships? Findings from the New Family Structures Study." Social Science Research 41(4):752-70.

Robinson, Joseph P., and Dorothy L. Espelage. 2011. "Inequities in Educational and Psychological Outcomes between LGBTQ and Straight Students in Middle and High School." Educational Researcher 40(7):315-30.

Rosenbaum, Paul R. 1984. "The Consequences of Adjustment for a Concomitant Variable That Has Been Affected by the Treatment." Journal of the Royal Statistical Society (Series A) 147(5):656-66.

Rosenfeld, Michael J. 2010. "Nontraditional Families and Childhood Progress through School." Demography 47(3):755-75.

Rosenfeld, Michael J. 2013. "Reply to Allen et al." Demography 50(3):963-69.

Rosenfeld, Michael J. 2014. "Couple Longevity in the Era of Same-Sex Marriage in the United States." Journal of Marriage and Family 76(5):905-18. 
Sarantakos, Sotirios. 1996. "Children in Three Contexts: Family, Education and Social Development." Children Australia 21(3):23-31.

Scheerens, Jaap, Melanie C. M. Ehren, Peter J. C. Sleegers, and Renske de Leeuw. 2012. "OECD Review on Evaluation and Assessment Frameworks for Improving School Outcomes: Country Background Report for the Netherlands." The Hague, the Netherlands: Dutch Ministry of Education.

Schumm, Walter R. 2018. Same-Sex Parenting Research: A Critical Assessment. London, UK: Wilberforce Publications.

Stacey, Judith, and Timothy J. Biblarz. 2001. "Does the Sexual Orientation of Parents Matter?" American Sociological Review 66(2):159-83.

Steenhof, Liesbeth, and Carel Harmsen. 2003. SameSex Couples in the Netherlands. Voorburg: Statistics Netherlands.

Stone, Amy L. 2019. "Frame Variation in Child Protectionist Claims: Constructions of Gay Men and Transgender Women as Strangers." Social Forces 97(3):1155-76.

Sullins, Paul D. 2015a. "Emotional Problems among Children with Same-Sex Parents: Difference by Definition." British Journal of Education, Society \& Behavioural Science 7(2):99-120.

Sullins, Paul D. 2015b. "The Unexpected Harm of SameSex Marriage: A Critical Appraisal, Replication and Re-analysis of Wainright and Patterson's Studies of Adolescents with Same-Sex Parents." British Journal of Education, Society \& Behavioural Science 11(2):1-22.

Trandafir, Mircea. 2014. "The Effect of Same-Sex Marriage Laws on Different-Sex Marriage: Evidence From the Netherlands." Demography 51(1):317-40.

Wainright, Jennifer L., Stephen T. Russell, and Charlotte J. Patterson. 2004. "Psychosocial Adjustment, School Outcomes, and Romantic Relationships of Adolescents with Same-Sex Parents." Child Development 75(6):1886-98.

Watkins, Caleb S. 2018. "School Progress among Children of Same-Sex Couples." Demography 55(3):799 821.

Weir, Bruce S., Amy D. Anderson, and Amanda B. Hepler. 2006. "Genetic Relatedness Analysis: Modern
Data and New Challenges." Nature Reviews Genetics 7:771-80.

Wodtke, Geoffrey T., Felix Elwert, and David J. Harding. 2016. "Neighborhood Effect Heterogeneity by Family Income and Developmental Period." American Journal of Sociology 121(4):1168-222.

Wodtke, Geoffrey T., David J. Harding, and Felix Elwert 2011. "Neighborhood Effects in Temporal Perspective: The Impact of Long-Term Exposure to Concentrated Disadvantage on High School Graduation." American Sociological Review 76(5):713-36.

Deni Mazrekaj is a postdoctoral researcher in sociology and social demography at the University of Oxford and an affiliated researcher at KU Leuven University in Belgium. He completed his $\mathrm{PhD}$ in economics in 2019 at $\mathrm{KU}$ Leuven. Deni is particularly interested in the returns to schooling and the role of family environment in the development of children's adult outcomes.

Kristof De Witte is a professor at the Faculty of Economics and Business at KU Leuven, Belgium, and he holds the chair in "Effectiveness and Efficiency of Educational Innovations" at United Nations University (UNU-MERIT) at Maastricht University, the Netherlands. De Witte is also a Fellow member of the CESifo Network (Ludwig-Maximilians-University and Ifo Institute), and of the Finish VATT Institute for Economic Research. At KU Leuven he is director of the research group "Leuven Economics of Education Research." De Witte's research interests comprise education economics, performance evaluation, and political economy.

Sofie Cabus is a research manager at KU Leuven, Research Institute for Work and Society (HIVA), a visiting professor at the University of Antwerp, and an affiliated researcher at Maastricht University. In 2013, she obtained her PhD in the economics of education at Maastricht University. Dr. Cabus mainly conducts research in the field of education and the labor market. This includes topics such as vocational education and training, adult education and training, and lifelong learning. She is an expert in evidence-based impact evaluations. 